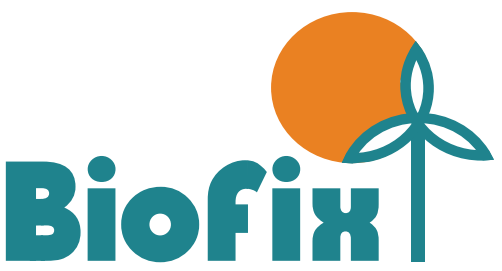

scientific journal

v. 2 n. 22017

Recebido em 13/09/2017

Aceito em 30/09/2017

Publicado em 09/10/2017

DOI: dx.doi.org/10.5380/biofix.v2i2.55223

\section{PERCOLADO DE NITRATO EM CAMBISSOLO ADUBADO COM DIFERENTES DOSES DE BIOSSÓLIDO}

\author{
PERCOLATE OF NITRATE IN CAMBISOL FERTILIZED \\ WITH DIFFERENT DOSES OF BIOSOIDS
}

Universidade Estadual do Centro-Oeste, Irati, Paraná, Brasil marcelosteffler@gmail.com ${ }^{1}$ \& kellygm77@gmail.com ${ }^{4}$

Universidade Estadual do Oeste do Paraná, Cascavel, Paraná, Brasil veniciosteffler@gmail.com ${ }^{2}$ \& mgueri@hotmail.com ${ }^{3}$

\section{RESUMO}

Uma das preocupações com o uso de lodo de esgoto no solo agrícola refere-se ao risco de poluição das águas subterrâneas causada pela lixiviação de nitrato, o que torna necessário mais pesquisas a esse respeito. Nesse contexto, o presente estudo objetivou avaliar o comportamento de três diferentes doses de biossólido oriundo da estação de tratamento de esgoto do Rio das Antas de Irati, Paraná. Foram misturados biossólido com Cambissolo nas dosagens de 2,5; 5,0; e 7,5\%; em seguida, as amostras foram inseridas em colunas de PVC com o fundo vazado, que permitiram a captação da água percolada para realização das análises de nitrato. Os resultados comprovaram que doses de até 25 t.ha $^{-1}$ não implicam em aumento significativo de nitrato no percolado, porém doses superiores a 80 t.ha $^{-1}$ não devem ser aplicadas, pois, segundo o modelo de regressão encontrado, essa aplicação resultaria em doses nocivas de nitrato nas águas subterrâneas. Recomenda-se que em estudos futuros aspectos referentes à capacidade de troca catiônica e o teor de nitrogênio no solo sejam correlacionados com a concentração de nitrato percolado, uma vez que podem afetar significativamente o comportamento do íon no horizonte do solo.

PALAVRAS-CHAVE: Adubação, Lodo de esgoto, Poluição do lençol freático.

\section{ABSTRACT}

One concern about sewage sludge disposal on soils is related to the contamination of groundwater caused by the nitrate leaching due to sludge mineralization, which demands more research on the subject. In this context, the present study aimed to evaluate the behavior of three different doses of biosolids from the sewage treatment station Antas' river of Irati, Paraná State, Brazil. The biosolids were mixed with a Cambisol at the dosages of 2.5, 5.0, and $7.5 \%$, then the samples were inserted into PVC columns with the leaked bottom that allowed the capture of the percolated water to perform the nitrate analyzes. The results showed that contents up to 25 t.ha $^{-1}$ do not imply a significant increase in nitrate in the percolate, but doses of more than $80 \mathrm{t}^{\mathrm{th}} \mathrm{a}^{-1}$ should not be applied because, according to the regression model found, this would result in harmful doses of nitrate in groundwater . It is recommended that in future studies aspects related to the cation exchange capacity and the nitrogen content in the soil are correlated with the percolated nitrate concentration, since they can significantly affect the ion behavior in the soil horizon.

KEYWORDS: Fertilizing, Sewage sludge, Pollution of groundwater. 


\section{INTRODUÇÃO}

A preocupação com a degradação ambiental proveniente de lançamentos de esgotos in natura tem contribuído para a maior sensibilização por parte da sociedade como vistas a preservação dos recursos naturais. Assim, diversos municípios brasileiros instalaram eficientes Estações de Tratamento de Esgoto (ETE) para o correto tratamento. Ainda assim, há preocupação com o lodo gerado no processo de tratamento da ETE, sendo um passivo ambiental que, caso não possuía uma forma correta de manejo, pode causar grandes danos ambientais.

Segundo Tsutiya (2001), os Estados Unidos da América (EUA) produzem cerca de 13 milhões de toneladas de biossólido (lodo drenado) por ano, em que a destinação final desse material segue para aterros sanitários (41\%), uso agrícola e condicionamento do solo (25\%), incineração (16\%), reflorestamento e recomposição de áreas degradadas (12\%) e disposição oceânica (5\%). Da mesma forma, a Europa produz 7 milhões de toneladas de biossólido por ano, cuja distribuição é semelhante à dos EUA, sendo $42 \%$ para agricultura, 36\% incinerados, 5\% dispostos no oceano e $6 \%$ para recuperação de áreas degradadas.

No Brasil, a produção de biossólido está entre 150 a 220 mil toneladas por ano (PREDOZA et al., 2011), sendo estimada a produção de $33 \mathrm{~g}$ de sólidos solúveis totais por habitante ao dia (MACHADO et al., 2004). A questão do manejo e da disposição final do lodo é um problema relativamente recente no Brasil e, por ser inerente ao tratamento de esgoto, tende ao agravamento na medida em que se implantam e operam as ETE (GODOY, 2013). Do lodo produzido no Brasil, cerca de $50 \%$ tem seu destino final para aterro sanitário, 15\% para agricultura e 35\% têm destino indefinido (MACHADO et al., 2004).

Segundo a Federação dos Trabalhadores em Empresas de Crédito do Paraná (FETECPR), o estado do Paraná apresentou uma produção estimada de cerca de 20 mil toneladas de lodo seco no ano de 2009, sendo que a capacidade de suporte em suas estações de tratamento de esgoto é de 38 mil toneladas. A produção e a utilização do lodo na cidade de Irati no mesmo ano foram estimadas em 360 toneladas de lodo seco por ano (FETECPR, 2009).

A Unidade de Gerenciamento de Lodo de Irati (UGL) funciona com licença do Instituto Ambiental do Paraná (IAP) desde o início do ano de 2009, com o intuito de receber a contribuição de lodo das cidades de Imbituva, Prudentópolis, Ivaí e Inácio Martins, além da própria Irati. O lodo tem destinação como incremento no solo de cultivo de feijão, milho, soja e também na produção de grama e reflorestamentos. Vale ressaltar que o lodo tratado passível de ser usado na agricultura deve atender as exigências da legislação vigente, como a Resolução CONAMA no 375 de 2006, passando a ser denominado de biossólido (CONAMA, 2006).

O biossólido atua como condicionador de solos e fertilizante, pois melhora a estrutura do mesmo (BARBOSA; TAVARES FILHO, 2006) e estimula a atividade microbiana, deixando o solo mais fértil (TRANNIN et al., 2008), aumentando os teores de matéria orgânica e influenciando positivamente a nutrição das plantas (ROCHA; SHIROTA, 2004). Em solos desgastados, a destinação do lodo visa à recuperação de áreas degradadas (FARIAS; SANTOS, 2007), incrementando o teor de nutrientes no solo, principalmente de carbono, fósforo e nitrogênio.

No entanto, uma preocupação oriunda da utilização do lodo de esgoto na agricultura é a mineralização do nitrogênio, oxidando-se a nitrato (OLIVEIRA et al., 2002), sendo que esse não é efetivamente absorvido pelos componentes do solo, deslocando-se facilmente pelo perfil do solo e podendo chegar aos mananciais subterrâneos (AYRES; WESTCOST, 1999).

A Organização Mundial da Saúde (OMS) e a Resolução CONAMA no 396 de 2008 estabelecem a concentração de nitrato máxima aceitável de $10 \mathrm{mg} \cdot \mathrm{L}^{-1}$ para água potável, sendo esse o padrão adotado no Brasil pela Comissão Nacional de Normas e Padrões para Alimentação do Ministério da Saúde (BRASIL, 1990; CONAMA, 2008).

A lixiviação de nitrato está associada a dois efeitos adversos para a saúde: 1) desenvolvimento da metemoglobinemia, especificamente em crianças, conhecida como síndrome do "bebê azul"; e 2) formação potencial de nitrosaminas e nitrosamidas carcinogênicas (BOUCHARD et al., 1992; FENG, 2005). Assim, o presente estudo objetivou determinar a relação entre diferentes doses de biossólido oriundo de uma ETE em Cambissolo, bem como as concentrações de nitrato em água percolada.

\section{MATERIAL E MÉTODOS}

\section{Instalação e condução do experimento}

Amostras de Cambissolo foram coletadas em profundidades de até $50 \mathrm{~cm}$, com auxílio de pá e trado do tipo calador, em uma área experimental de plantio de Pinus taeda L. com 18 anos de idade e cultivada nas dependências da Universidade Estadual do Centro-Oeste (UNICENTRO), campus Irati. O biossólido (lodo desidratado) foi obtido na Estação de Tratamento de Esgoto do Rio das Antas do município de Irati, após o 
tratamento pelo processo N-viro (N-VIRO INTERNATIONAL INC, 2004).

Após as coletas de solo, três tratamentos foram elaborados com as dosagens de $2,5 \%, 5 \%$ e $7,5 \%$, os quais

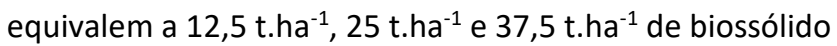
e um tratamento controle preenchido somente com solo. As doses de lodo foram determinadas com base nas aplicações de biossólido praticáveis na agricultura e regulamentada pela Resolução CONAMA no 375 de 2006.

As misturas foram realizadas em triplicata e acondicionadas em colunas, que foram preenchidas a partir da base. Tais colunas foram confeccionadas a partir de canos de PVC com diâmetro de $7,1 \mathrm{~cm}$ e altura de $50 \mathrm{~cm}$ (Figura 1). Os tratamentos continham $2 \mathrm{~kg}$ de mistura (solo e biossólido), sendo a quantidade de biossólido de $50 \mathrm{~g}$, 100 g e 150 g, respectivamente.

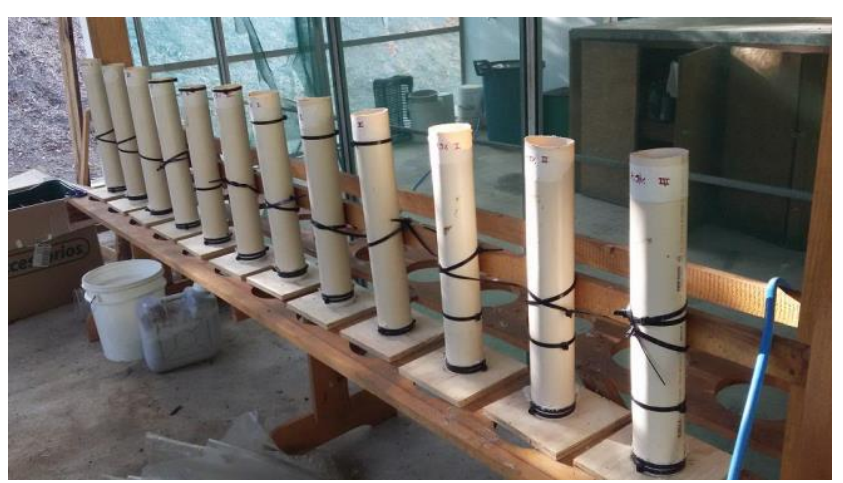

Figura 1. Esquema de montagem e de operação das colunas preenchidas com solo e biossólido.

Após preenchidas, as colunas com solo e biossólido permaneceram por 180 dias em repouso para estabilização das misturas. A partir disso, $110 \mathrm{~mL}$ de água deionizada foram adicionadas em cada coluna diariamente durante um mês, sendo esse o volume equivalente da pluviosidade total do mês mais chuvosos do ano em Irati (PR), segundo dados do Banco de Dados Meteorológicos para Ensino e Pesquisa (BDMEP, 2016), conforme metodologia proposta por Santibáñez et al. (2007), que adicionaram a quantidade de água nas colunas equivalente à precipitação média da região central do Chile.

\section{Coletas de solos e análises químicas}

A área de plantio de Pinus taeda. foi dividida em quatro parcelas de $100 \mathrm{~m}^{2}$ cada. Dentro delas, amostras de solo foram coletadas em cinco pontos aleatórios, obtendo-se uma amostra composta de cada parcela. Essas amostras foram analisadas no Laboratório de Análises de Rotina de Solos da UNICENTRO, campus de Irati (PR).
A metodologia utilizada para a obtenção da matéria orgânica foi a digestão úmida. O Fósforo (P) e o Potássio (K) foram extraídos com solução de Mehlich-I, ao passo que o $\mathrm{pH}$ em $\mathrm{CaCl}_{2}$ de 1:2:5, o Cálcio (Ca), o Magnésio ( $\mathrm{Mg}$ ) e o Alumínio (Al) trocáveis extraídos com $\mathrm{KCl} 1 \mathrm{~mol} . \mathrm{L}^{-1}$ (EMBRAPA, 1999). As amostras de água percolada foram coletadas e conservadas abaixo de $4^{\circ} \mathrm{C}$ em geladeira. Após dois dias, as análises de nitrato foram realizadas pelo método ultravioleta de triagem espectrofotométrica (APHA, 1999).

\section{Delineamento experimental e análise de dados}

Os dados foram avaliados com auxílio do programa $R$ (versão 2.13.0) em um delineamento inteiramente casualizado, por meio de análise de variância, teste de Tukey para comparação de médias a $5 \%$ de significância e modelos de regressão linear. As premissas de homogeneidade de variância, normalidade de resíduos e ausência de colinearidade foram checadas mediante os testes de Bartlett, Shapiro-Wilks e Durbin-Watson, respectivamente, em que valores de probabilidade superiores a $5 \%$ foram considerados significativos.

\section{RESULTADOS E DISCUSSÃO}

As análises físico-químicas do solo amostrado estão descritas na Tabela 1. De forma geral, o solo foi considerado distrófico, sendo carente de nutrientes, pois apresentou saturação por bases (V\%) inferior a 50\%, em que solos com V\% superior a $50 \%$ são considerados altamente produtivos, portanto eutróficos. $\mathrm{O} \mathrm{pH}$ foi considerado ácido e a textura argilosa, cuja porcentagem de argila de $51 \%$ (g/100g) está compreendida entre 35 e $60 \%$. Ainda, apresentou menos de $15 \%$ de areia quando somado os dois tipos de areia (EMBRAPA, 1999).

Tabela 1. Médias e desvios padrões dos parâmetros físicoquímicos das amostras do solo avaliado

\begin{tabular}{cc}
\hline Dados & Solo avaliado \\
\hline $\mathrm{pH} \mathrm{em} \mathrm{CaCl} 2$ & $4,2 \pm 0,08$ \\
Saturação por bases (g/100g) & $36,1 \pm 3,41$ \\
Areia Grossa (g/100g) & $3,35 \pm 0,83$ \\
\hline Areia Fina (g/100g) & $2,73 \pm 0,57$ \\
\hline Silte (g/100g) & $42,93 \pm 3,97$ \\
Argila (g/100g) & $51 \pm 3,83$ \\
\hline Densidade & $1,01 \pm 0,03$ \\
\hline
\end{tabular}

As concentrações de nitrato encontradas no percolado estão apresentadas na Tabela 2, as quais apresentaram 
aumento na concentração conforme acréscimo da dose de biossólido. De forma geral, o Nitrato percolado formou dois grupos estatisticamente distintos, o primeiro formado pelas três primeiras dosagens e o último composto pela dosagem de 37,5 t.ha-1.

Confrontando os dados do presente estudo com a literatura constatou-se que, em Latossolo Distrófico de textura média, também se verificou que os tratamentos com lodo de esgoto aumentaram significativamente a concentração de nitrato $\left(\mathrm{N}-\mathrm{NO}_{3}\right)$ no percolado a 30 e $60 \mathrm{~cm}$ de profundidade (CARVALHO-OLIVEIRA et al., 2001). Os autores ainda constataram que a aplicação de doses de lodo a partir de 33 t.ha-1 ocasionou riscos de poluição das águas subterrâneas com nitrato, pois apresentou valores superiores a $10 \mathrm{mg} \cdot \mathrm{L}^{-1}$.

Tabela 2. Médias e desvios padrões das concentrações de nitrato percolado em Cambissolo tratado com diferentes doses de biossólido

\begin{tabular}{cccc}
\hline \multirow{2}{*}{ Tratamentos } & \multirow{2}{*}{ Variável } & Média & \multicolumn{2}{c}{ Desvio padrão } \\
\cline { 3 - 4 } & & \multicolumn{2}{c}{$\left(\mathrm{mg}^{\left.-\mathrm{L}^{-1}\right)}\right.$} \\
\hline Controle & Nitrato & $2,99 \mathrm{~b}$ & $\pm 0,028$ \\
12,5 t.ha $^{-1}$ & Nitrato & $3,01 \mathrm{~b}$ & $\pm 0,097$ \\
25 t.ha $^{-1}$ & Nitrato & $3,16 \mathrm{~b}$ & $\pm 0,031$ \\
37,5 t.ha $^{-1}$ & Nitrato & $5,86 \mathrm{a}$ & $\pm 0,215$ \\
\hline
\end{tabular}

Médias seguidas da mesma letra não diferem estatisticamente pelo teste de Tukey a $5 \%$ de significância.

Segundo o modelo de regressão linear para o Nitrato encontrado neste estudo (Figura 2), a contaminação da água com nitrato ocorre com a aplicação de 80 t.ha $^{-1}$ de biossólido no solo. Quando aplicado valores nessa faixa na equação da regressão linear obtida (Eq. 1), os resultados apontam para concentrações de nitrato superiores ao permitido pela Resolução CONAMA no 375/06, sendo de $10 \mathrm{mg} \cdot \mathrm{L}^{-1}$.

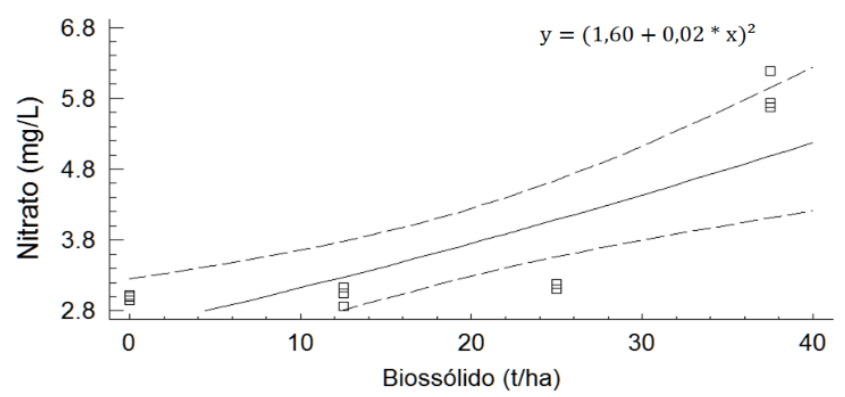

Figura 2. Regressão para diferentes concentrações de biossólido no solo e respectiva concentração de nitrato na água percolada.

Foi possível obter a regressão apresentada na equação
(1) com $R^{2}$ de 0,81 .

$$
\left[\mathrm{N}-\mathrm{NO}_{3}\right]=(1,60+0,02 \times \text { Biossolido })^{2}
$$

Em que:

[N-NO $\left.\mathrm{NO}_{3}\right]=$ concentração de nitrato na água percolada (mg. $\left.\mathrm{L}^{-1}\right) ; \mathrm{e}$

Biossólido = tonelada de biossólido por hectare.

Luczkiewicz (2006) afirmou que solos com menores densidades retêm menores quantidades de nitrato, em que, à medida que aumenta a densidade do solo, diminuise a quantidade de macroporos e o fluxo do permeado torna-se cada vez mais lento, permitindo a conversão de nitrogênio orgânico em nitrato. Para ilustrar tal informação, a densidade do solo deste estudo é de 1,01 g. $\mathrm{cm}^{-3}$, enquanto a densidade do solo de Carvalho-Oliveira et al. (2001) foi de 1,32 $\mathrm{g} . \mathrm{cm}^{-3}$, assim maiores densidades resultam em maiores concentrações de nitrato.

Inúmeros fatores exercem influência para a lixiviação no Nitrato, destacam-se: 1) fatores climáticos; 2) estado inicial do solo; 3) métodos de irrigação; e 4) textura do solo. Andrade et al. (2009) destacaram que o íon nitrato tem maior índice de lixiviação, por não ser adsorvido pelos componentes da fração do solo, sendo apenas adsorvidos pelas raízes das plantas ou, ainda, percolam até águas subterrâneas.

\section{CONCLUSÕES}

As aplicações de biossólido não aumentam significativamente a concentração de nitrato em Cambissolo até 25 t.ha-1. Aplicações acima de 80 t.ha $^{-1}$ não são recomendadas, pois resultam em concentrações de percolado de nitrato acima de $10 \mathrm{mg} \cdot \mathrm{L}^{-1} \mathrm{e}$, portanto, são consideradas de risco para a população, pois superam o limite máximo permitido para águas de consumo humano.

Recomenda-se que estudos futuros relacionem a concentração de percolado de nitrato com maior variedade de parâmetros físico-químicos de solos adubados com o biossólido. Embora a Resolução CONAMA no 375/06 estabeleça sobre o uso e a aplicação de biossólido para adubação agrícola, não faz recomendações referentes aos aspectos químicos dos solos, havendo apenas informações sobre características texturais.

Os resultados do presente estudo, quando comparados com a literatura disponível, levantam a hipótese de que, tanto os aspectos referentes a capacidade de troca catiônica como o teor de nitrogênio no solo podem afetar significativamente o comportamento de nitrato. 


\section{REFERÊNCIAS}

ANDRADE, E. M.; AQUINO, D. N.; CRISOSTOMO L. A.; RODRIGUES, J. O.; LOPES, F. O. Impacto da lixiviação de nitrato e cloreto no lençol freático sob condições de cultivo irrigado. Ciência Rural, v. 39, n. 1, p. 88-95, 2009.

AYRES, R. S.; WESTCOT, D. W. A qualidade da água na agricultura. 2. ed. Campina Grande: UFPB, 1999. 153 p.

APHA - American Public Health Association. Standard methods for the examination of water and wastewater. American Public Health Association, American Water Works Association, Water Environmental Federation, 21. ed. Washington, 2005.

BDMEP - Banco de Dados Meteorológicos para Ensino e Pesquisa Série histórica de dados diários de precipitação de Irati - PR. Disponivel em: <http://www.inmet.gov.br/projetos/rede/ pesquisa>. Acesso em: 10/09/2016.

BARBOSA, G. M. C.; TAVARES FILHO, J. Uso agrícola do lodo de esgoto: influência nas propriedades químicas e físicas do solo, produtividade e recuperação de áreas degradadas. Semina: Ciências Agrárias, v. 27, n. 4, p. 565-579, 2006.

BOUCHARD, D. C.; WILLIAMS, M. K.; SURAMPALLI, R. Y. Nitrate contamination of groundwater; sources and potential health effects. Journal of the American Water Works Association, v. 84, n. 9, p. 85-90, 1992.

BRASIL. Ministério da Saúde. Divisão Nacional de Vigilância Sanitária de Alimentos. Portaria no 36-SVS/MS, de 19 de janeiro de 1990. In: Associação Brasileira de Indústrias de Alimentação. Compendio de legislação de alimentos. São Paulo: ABIA, 1990. p. 711-777.

CARVALHO-OLIVEIRA, F.; MATTIAZZO, M. E.; MARCIANO, R.; MORAES, S. O. Lixiviação de nitrato em um Latossolo Amarelo distrófico tratado com lodo de esgoto e cultivado com cana-deaçúcar. Scientia Agricola, v. 58, n. 1, p. 171-180, 2001.

CONAMA - Conselho Nacional Do Meio Ambiente. Resolução no 375 de 29 de agosto de 2006. Define critérios e procedimentos, para o uso agrícola de lodos de esgoto gerados em estações de tratamento de esgoto sanitário e seus produtos derivados, e dá outras providências. Diário Oficial da União, 2006.

CONAMA - Conselho Nacional Do Meio Ambiente. Resolução no 396 de 3 de abril de 2008. Dispõe sobre a classificação e diretrizes ambientais para o enquadramento das águas subterrâneas e dá outras providências. Diário Oficial da União, 2008.

EMBRAPA - Empresa Brasileira de Pesquisa Agropecuária. Sistema brasileiro de classificação de solos. Rio de Janeiro: EMBRAPA Solos, 1999. 412 p.

FARIAS, P.H.S.; SANTOS, H.I. Uso do lodo primário de esgoto urbano de ETE's na recuperação de áreas degradadas. Goiânia: Universidade Católica de Goiás, 2007. 14 p.

FENG, Z. Z. Soil $\mathrm{N}$ and salinity leaching after the autumn irrigation and its impact on groundwater in Hetao Irrigation District, China. Agricultural Water Management, v. 71, p. 131-143, 2005.
GODOY, E. L. de. Uso agronômico do lodo de esgoto na recuperação de área degradada: Efeito residual. 98 f. 2008. Tese (Doutorado em Agronomia) - Universidade Federal de Goiás, Goiânia, 2008.

ŁUCZKIEWICZ, A. Soil and groundwater contamination as a result of sewage sludge land application. Polish Journal of Environmental Studies, v. 15, n. 6, p. 869-876, 2006.

MACHADO, M. F. S.; FIGUEIREDO, R. F.; CORAUCCI-FILHO, B. Produção brasileira de lodos de esgotos. Sanare, v. 22, p. 66-74, 2004.

N-VIRO INTERNATIONAL INC. N-Viro operations manual. Toledo. 2004. Disponível em: < https://nvirointernational.wordpress.com/>. Acesso em: 20/09/2016

OLIVEIRA, F. C.; MATTIAZZO, E. M.; MARCIANO, R. C., ROSSETO, R. Efeito de aplicações sucessivas de lodo de esgoto em um Latossolo amarelo distrófico cultivado com cana-de-açúcar: carbono orgânico, condutividade elétrica, pH e CTC. Revista Brasileira de Ciência do Solo, v. 26, p. 505-519, 2002.

PEDROZA, M. M.; VIEIRA, G. E. G.; SOUSA, J. F.; PICKLER, A. C.; LEAL, E. R. M.; MILHOMEN, C. C. Produção e tratamento de lodo de esgoto - uma revisão. Revista Liberato, v. 11, n. 16, p. 89-188, 2010.

ROCHA, M. T.; SHIROTA, R. Disposição final de lodo de esgoto. Revista de Estudos Ambientais, v. 1, n. 3, p. 1-24, 2004.

R DEVELOPMENT CORE TEAM. R: a language and environment for statistical computing. R Foundation for Statistical Computing. Versão 2.13.0. Disponível em: <www.R-project.org $>$. Acesso em: $13 / 10 / 2016$.

SANTIBÁÑEZ, C.; GINOCCHIO, R.; VARNERO, M. T. Evaluation of nitrate leaching from mine tails amended with biosolids under Mediterranean type climate conditions. Soil Biology and Biochemistry, v. 39, n. 6, p. 1333-1340, 2007.

TRANNIN, I. C. B.; SIQUEIRA, J. O.; MOREIRA, F. M. S. Atributos químicos e físicos de um solo tratado com biossólido industrial e cultivado com milho. Revista Brasileira de Engenharia Agrícola e Ambiental, v. 12, p. 223-230, 2008.

TSUTIYA, M.T. Biossólidos na agricultura. 1.ed. São Paulo: SABESP, 2001. 468 p. 